\title{
Awareness of cord blood collection and the impact on banking
}

\author{
Rusha Bhandari $^{1}$ | Amy Lindley ${ }^{2}$ | Deepika Bhatla ${ }^{2}$ | Aleksandar Babic ${ }^{2,3}$ \\ Kathy Mueckl ${ }^{3}$ | Rakesh Rao ${ }^{1,4}$ | Paula Brooks ${ }^{4}$ | Vicki Geiler ${ }^{3}$ | Gilad Gross ${ }^{5}$ | \\ Mohamad Al-Hosni ${ }^{2,5}$ | Shalini Shenoy ${ }^{1}$
}

${ }^{1}$ Washington University School of Medicine and St. Louis Children's Hospital, St. Louis, Missouri

${ }^{2}$ Saint Louis University School of Medicine and SSM Health Cardinal Glennon Children's Hospital, St. Louis, Missouri

${ }^{3}$ St. Louis Cord Blood Bank, St. Louis, Missouri

${ }^{4}$ Missouri Baptist Hospital, St. Louis, Missouri

${ }^{5}$ SSM Health St. Mary's Hospital, St. Louis, Missouri

Correspondence

Shalini Shenoy, Department of Pediatrics, Washington University School of Medicine, Box 8116, 660 S. Euclid Ave., St. Louis, MO 63110.

Email: shenoy@wustl.edu

\begin{abstract}
Background: Umbilical cord blood (UCB) is an important source of hematopoietic stem cells for transplantation especially in minority populations with limited chances of finding a histocompatible volunteer donor in the registry. UCB has the advantages of early availability, successful outcomes despite some histocompatibility mismatch, and low incidence of chronic graft-versus-host disease. Public cord blood banks that disseminate UCB products for transplant depend on voluntary donation at participating hospitals and obstetrical providers for collection.
\end{abstract}

Procedure: Using survey questionnaires, we evaluated attitudes toward UCB donation, the frequency of donation, and provider opinions on UCB collection in the greater St. Louis metropolitan area that caters to minority ethnicities in significant numbers.

Results: Our data suggest that nervousness and lack of information regarding the donation and utility of the product were ubiquitous reasons for not donating. Additionally, irrespective of age or level of education, women relied on healthcare providers for information regarding UCB donation. Providers reported primarily time constraints to discussing UCB donation at prenatal visits (54\%). Of the interviewees, $62 \%$ donated UCB. Fallout due to refusal or preferring private banking was miniscule.

Conclusions: These results suggest that dedicated personnel focused on disseminating information, obtaining consent, and collecting the UCB product at major hospitals can enrich cord blood banks especially with minority cords. Sustained and focused efforts could improve upon a relatively high wastage rate and ensure a robust supply of UCB products at local public banks.

\section{KEYWORDS}

cord blood banks, umbilical cord blood

\section{1 | INTRODUCTION}

A number of malignant and nonmalignant disorders can be cured or stabilized with allogeneic hematopoietic stem cell transplantation (HSCT). ${ }^{1}$ Outcomes following HSCT have also significantly improved in the modern era of comprehensive supportive care, new conditioning regimens, and better identification and treatment of complications. As a result, application of HSCT has increased in the past decade particularly in the pediatric population, for both malignant and nonmalignant disorders. $^{2}$

Abbreviations: DCC, delayed cord clamping; GVHD, graft-versus-host disease; HLA, human leukocyte antigen; HSCT, hematopoietic stem cell transplant; MRD, matched related donor; SLCBB, St. Louis Cord Blood Bank; UCB, umbilical cord blood; URD, unrelated donor
The best outcomes following HSCT are noted in human leukocyte antigen (HLA) matched transplants from siblings or family members. ${ }^{3}$ However, fewer than $30 \%$ of patients have a suitable matched related donor (MRD). ${ }^{4}$ In the absence of MRD, HLA-matched unrelated donors (URDs) are utilized and survival outcomes following URD HSCT are quite comparable to those following MRD HSCT. ${ }^{5}$ URD HSCT is dependent on registries that enlist voluntary donors and access public umbilical cord blood (UCB) banks. ${ }^{6}$ Though slower than marrow to engraft and immune reconstitute, UCB transplants tolerate HLA mismatch, have a lower incidence of graft-versus-host disease (GVHD), and ultimately equivalent survival., 5 The higher cost of the UCB product upfront is potentially mitigated with time due to the absence of prolonged therapy for chronic GVHD. ${ }^{8}$ In addition, UCB can be acquired quickly at no donor risk and has low virus transmission potential. ${ }^{9}$ 
Further, cord blood banks hold promise for future stem cell endeavors in the advancement of science.

Increasing the diversity and number of banked UCB products is critical to serve transplant needs especially in minority recipients unable to find suitable histocompatible voluntary donors. Currently, it is estimated that 58 and $24 \%$ of African American children and adults, respectively, find suitable (5/6 or $6 / 6$ matches) UCB products in the registry maintained by the National Marrow Donor Program (NMDP), whereas very few $(<20 \%)$ find suitable voluntary donors. ${ }^{4}$ The Stem Cell Therapeutic and Research Act of 2005 was enacted to provide for the collection and maintenance of 150,000 new UCB units so they could be available for transplant. It aimed in particular to increase racial and ethnic diversity amongst UCB donors via education, outreach, and recruitment programs.

The goal of this study was to assess efforts at public banking of UCB products in the metropolitan St. Louis (Missouri) region and identify factors that could be targeted to increase public UCB banking in the region. We conducted a survey of potential donors and medical care providers at three large metropolitan hospitals regarding their opinions on UCB donation. We also reviewed UCB banking practices at the St. Louis Cord Blood Bank (SLCBB), a high functioning public UCB bank that was the repository for UCB products collected at these hospitals.

\section{2 | METHODS}

This study was approved by the Human Research Protection Office at each participating institution. Eligible subjects were women presenting for third trimester ultrasounds and those in the postpartum unit. Following consent, the women were asked to complete a survey assessing knowledge of and willingness to donate UCB (Table 1). Surveys were administered by a resident physician at Barnes Jewish Hospital, resident physician or staff nurse at SSM Health St. Mary's Hospital, and by a labor and delivery staff nurse at Missouri Baptist Medical Center. All responses were collated and stratified by age (less than or $\geq$ 30 years) and education (high school only or some college education). Age and education strata were used to determine if opinions and practice differed based on these variables. Providers included nurses, nurse practitioners, and physicians who responded to provider-specific questionnaires administered by the same personnel (Table 1). All surveys were anonymous and categorized by respondent details as above. No personal identifiers were collected from the responders.

\section{3 | RESULTS}

The three participating urban hospitals from the metropolitan St. Louis city were major contributors to the SLCBB and conducted 10,733 deliveries in 2015 , accounting for $39 \%$ of the total deliveries in the region. These hospitals, as a function of their location, care for an urban population that is racially diverse (Table 3 ).

Surveys were completed between April and November 2015 by 67 providers and 222 potential UCB donors. Provider responses were grouped by profession. Only $50 \%$ of the physicians reported discussing UCB donation during prenatal visits (Table 2). The majority (84\%) did so at the third trimester visits and recommended donation to public banks (87\%). The primary obstacle cited to providing patients with information on UCB donation was time; $62 \%$ of the physicians and $29 \%$ of the nurses identified time constraints as a major barrier to discussing UCB banking. The most frequent reasons that providers gave for failure to collect UCB at the time of delivery were also related to time constraints ( $\geq 40 \%$ ) (Table 2 ). Additional reasons, also related to the former, included the complexity of the collection process, lack of personnel, and decreased enthusiasm for the paperwork involved. Medical conditions precluding donation were less commonly cited as reasons for not discussing UCB donation.

Potential UCB donors were divided into four groups based on age and education. Group 1: age less than 30 years with high school education. Group 2: age less than 30 years with college education. Group 3: age 30 years or older with high school education. Group 4: age 30 years or older with college education. Respondent demographics and donation status are detailed in Table 3. Donation rates ranged between 58 and $73 \%$. The lowest rate of donation (58\%) was noted in women less than 30 years of age and without college education (Group 1). In this group, $94 \%$ of the respondents identified themselves as members of minority communities. In all groups, only about half of the respondents indicated that the benefits of UCB donation were discussed with them during prenatal visits. Similarly, providers also indicated that UCB donation was discussed in the antenatal period $50 \%$ of the time (Table 2). All donors donated to the local public bank except one from Group 2, who reported UCB storage in a private bank but did not provide a rationale for doing so.

Additional questions investigated awareness of and willingness to donate UCB further as shown by group in Figure 1. Among respondents from Group 1 ( $<30$ years with high school education), 65\% heard about UCB collection and storage from a healthcare provider. Only $8 \%$ cited a television or Internet source. In Group 2 ( $<30$ years with college education), $61 \%$ learned of UCB donation primarily from a healthcare provider; $16 \%$ were informed by media. In Group 3 (>30 years with high school education), $73 \%$ relied on healthcare providers to learn about UCB collection and storage; $20 \%$ indicated media as an information source. In Group 4 ( $\geq 30$ years with college education), $68 \%$ still relied on healthcare providers for information, though older and more educated. Only $15 \%$ were informed by media-related effort. Thus, there was no significant difference in response between groups irrespective of age or education (Figs. 1A, 1D, 1G, and 1J).

When the participants were questioned about reasons for not donating (Figs. 1B, 1E, $1 \mathrm{H}$, and $1 \mathrm{~K}$ ), lack of adequate information was the most common single reason provided by all groups. Education status may have influenced this response positively to a small degree, but the difference was not statistically significant. Women in Group 2 (the educated younger) and Group 4 (the educated older) implicated lack of information regarding UCB donation and storage 10 and $18 \%$ of the time, respectively, whereas women with less than college education (Groups 1 and 3) indicated the same 26 and 50\% of the time, respectively. This corroborated with answers to a question enquiring about how well the purpose and process of UCB collection was understood. 


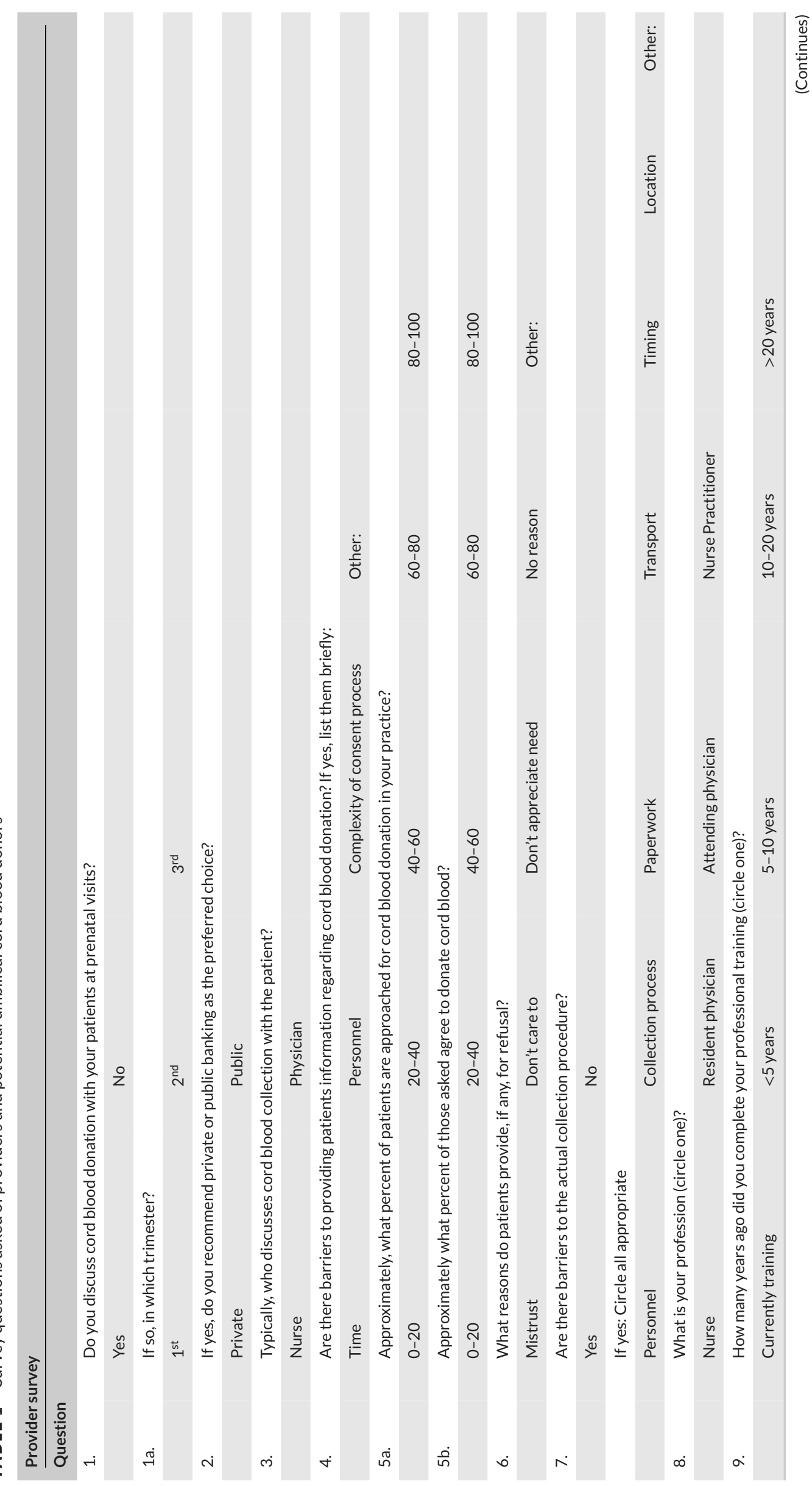


$\bar{\Phi}$
$\overline{ \pm}$

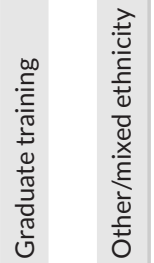

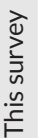

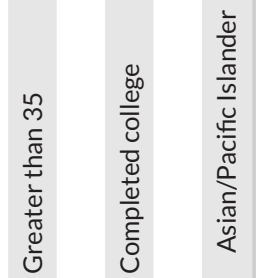

$\gtrless$

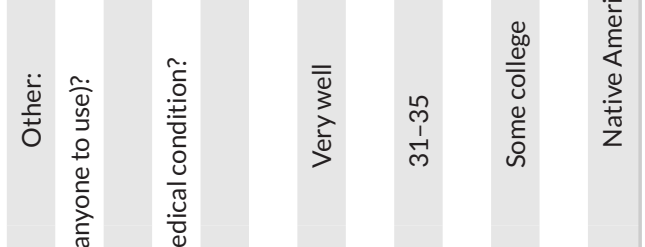

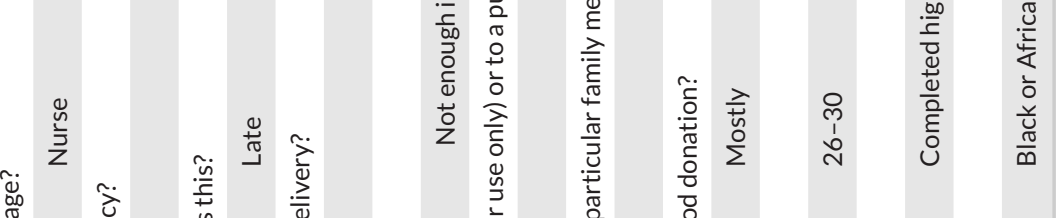

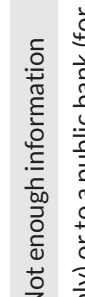

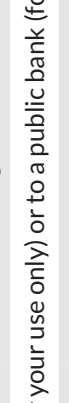

$\stackrel{\sigma}{+}$

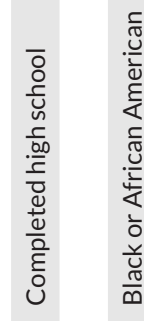

要

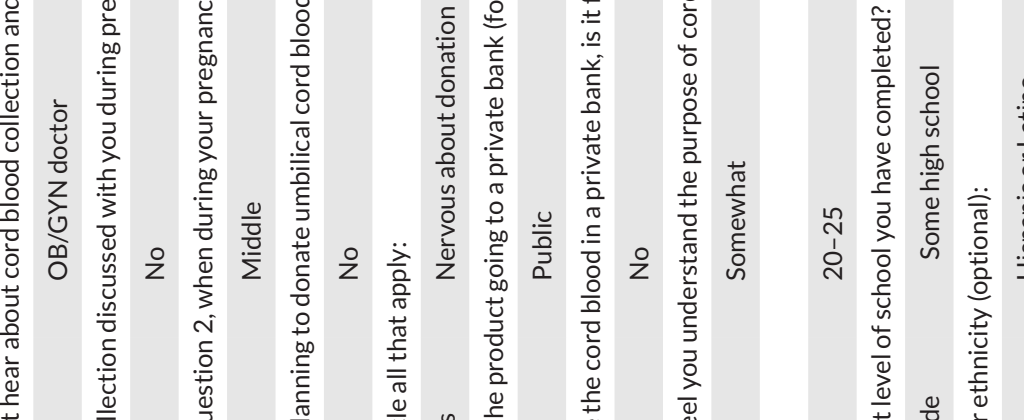

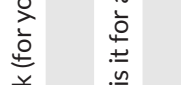

产

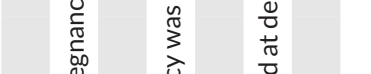

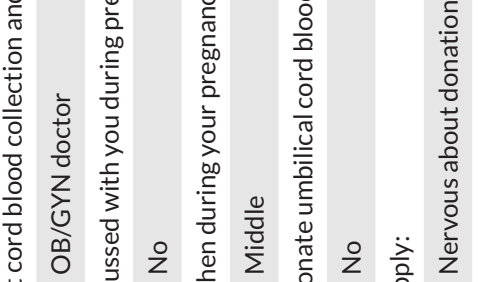

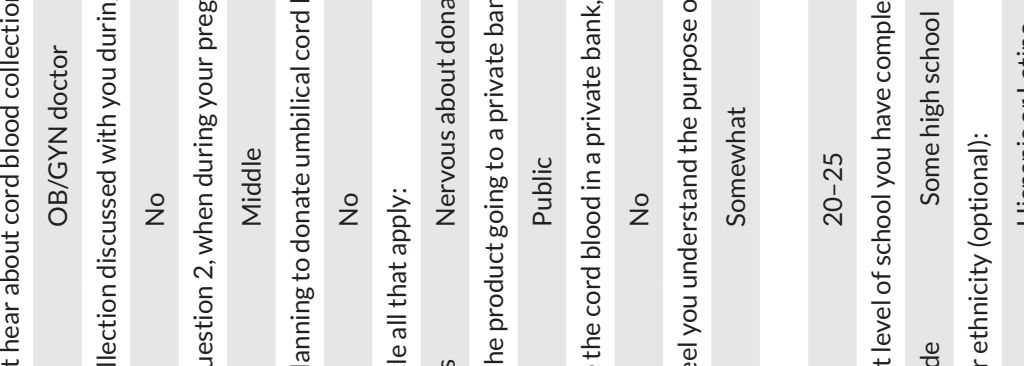

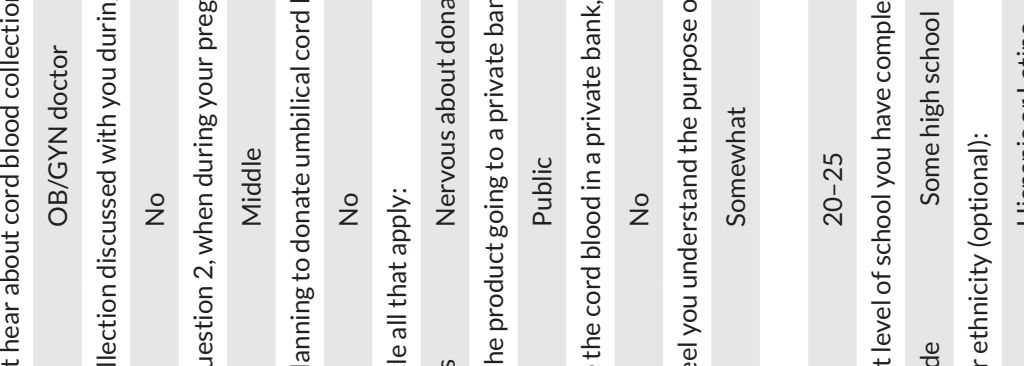

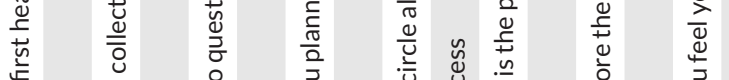

BHANDARI ET AL.

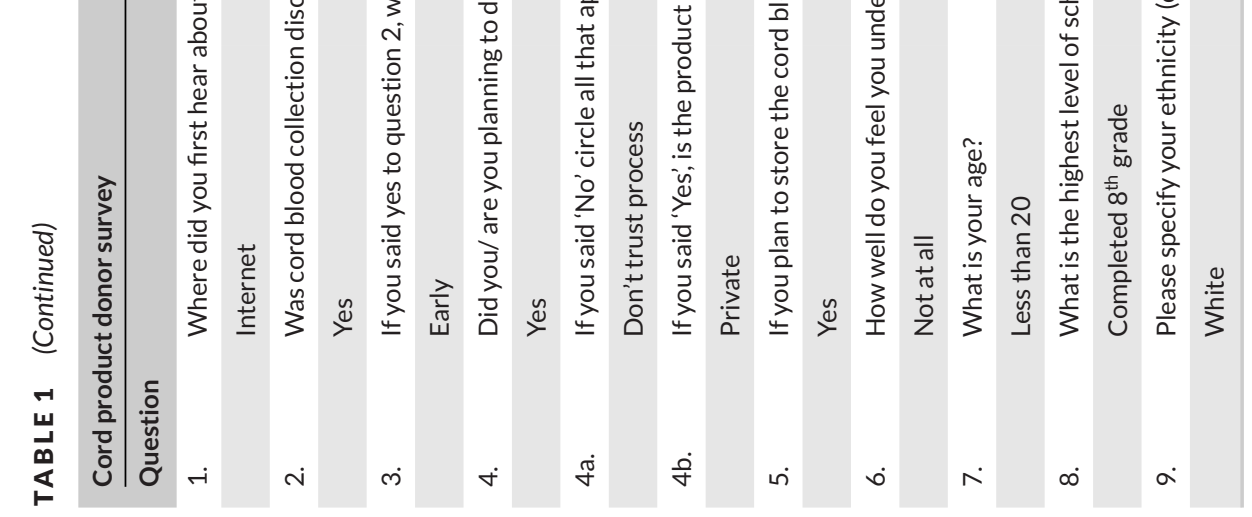


TABLE 2 Provider responses

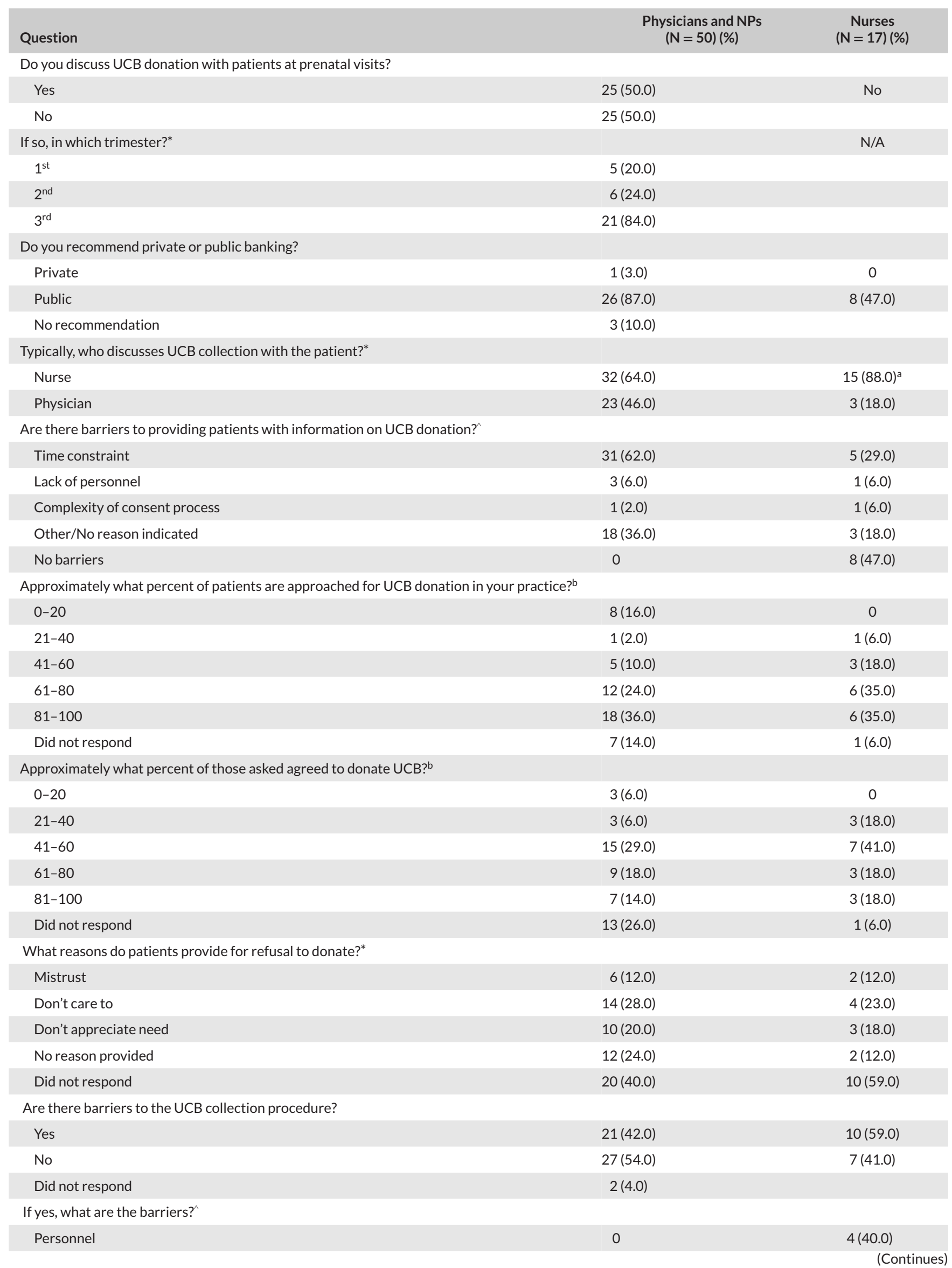


TABLE 2 (Continued)

\begin{tabular}{|lcc} 
Question & \multicolumn{1}{c}{$\begin{array}{c}\text { Physicians and NPs } \\
(\mathbf{N}=50)(\%)\end{array}$} & $\begin{array}{c}(\mathbf{N}=17)(\%) \\
\text { Collection process }\end{array}$ \\
\hline Paperwork & $6(29.0)$ & $1(20.0)$ \\
\hline Transport & $1(5.0)$ & 0 \\
\hline Time involved & $2(10.0)$ & $4(40.0)$ \\
\hline Location & $9(43.0)$ & 0 \\
\hline Did not indicate any of above & $2(10.0)$ & $3(30.0)$ \\
\hline
\end{tabular}

$\mathrm{N}$, number; NP, nurse practitioner.

*At least one responder gave more than one answer to this question.

${ }^{a}$ We believe that the responders indicated that other nurses did discuss donation but not them personally.

${ }^{\text {b }}$ One person chose multiple responses.

`Some respondents perceived multiple barriers.

TA B LE 3 Demographics and donation history of potential donors of UCB products

\begin{tabular}{|c|c|c|c|c|}
\hline & $\begin{array}{c}\text { Group I: }<30 \text { years } \\
\text { old and }<\text { HS } \\
\text { education }\end{array}$ & $\begin{array}{c}\text { Group II: }<30 \text { years } \\
\text { old and }>\text { HS } \\
\text { education }\end{array}$ & $\begin{array}{c}\text { Group III: }>30 \text { years } \\
\text { old and } \leq \mathrm{HS} \\
\text { education }\end{array}$ & $\begin{array}{c}\text { Group IV: }<30 \text { years } \\
\text { old and }>\text { HS } \\
\text { education }\end{array}$ \\
\hline Total respondents & 80 & 74 & 15 & 53 \\
\hline White & 7 & 27 & 1 & 27 \\
\hline Minority & 72 & 47 & 14 & 25 \\
\hline White & 6 & 17 & 0 & 20 \\
\hline Minority & 40 & 28 & 11 & 16 \\
\hline
\end{tabular}

HS, high school.

Between 41 and $67 \%$ of the respondents from all groups indicated that they understood very little to nothing about banking UCB that is otherwise discarded or the potential advantages to society at no additional cost to them (Figs. 1C, 1F, 1I, and 1L). Nervousness regarding UCB donation was significantly higher in respondents from Groups 1 and 2 (younger donors) compared with Group $4(P=0.0004$ and 0.02 , respectively).

Additional reasons for not donating when specified included a reluctance to spend time completing the paperwork formalities and that they were not requested to do so by providers. Only one respondent cited delayed cord clamping (DCC) (which does not preclude collection) as a reason for not donating.

We compared changes in collection and banking volumes at SLCBB at two time points 10 years apart by reviewing collected data from 2005 and 2015, since the Stem Cell Therapeutic and Research Act of 2005 was established in the interval. In 2005, the SLCBB collected 6,883 units, of which 932 (13\%) were from minority donors. Of those collections, $27 \%$ of minority and $25 \%$ of Caucasian units met the criteria for storage and 1,756 products $(26 \%)$ were banked. In $2015,37 \%$ of deliveries yielded UCB products from participating hospitals to the SLCBB. Of the women who donated, $3 \%$ were younger than 20 years and 50\% were $20-30$ years of age. These products accounted for 15,424 units (an increase of $124 \%$ from 2005), of which 3,851 (25\%) were from minorities. Of the collection, however, only $9 \%$ of minority and $7 \%$ of Caucasian units met the criteria for banking, ultimately resulting in 1,181 products $(8 \%)$ being banked. This decrease in the actual rate of storage was largely due to stricter banking criteria in relation to cell dose and viability. As the utilization of UCB grafts increased and the factors affecting outcomes such as cell dose were established, cryopreservation guidelines were restricted to cords with higher cell doses to provide adequate products for transplant, especially in adult recipients.

\section{4 | DISCUSSION}

We evaluated the UCB collection in the metropolitan St. Louis area from donor and banking perspectives with the goal of identifying interventions to increase UCB donation. The region is ethnically diverse and conducive to the goal of increasing minority UCB donations. From this survey, we found that approximately $50 \%$ of all women felt wellinformed about UCB donation and the main source of information irrespective of age and education level was acquired from healthcare providers. Using provider-specific questions, we also found that UCB donation is discussed with potential donors approximately $50 \%$ of the time, largely due to time constraints. This resulted in respondent mothers indicating that lack of information was a major barrier to donation. It was encouraging to note that lack of trust, interest in private banking, or other beliefs did not obstruct donation irrespective of age or education level of the women surveyed. 
Group 1: Under 30 years with up to high school education

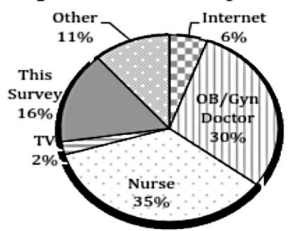

A

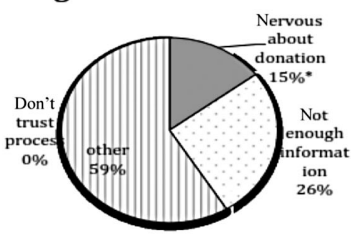

B

${ }^{*} P=0.0004$

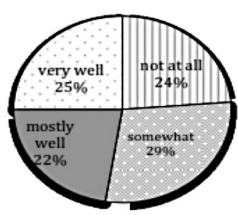

C

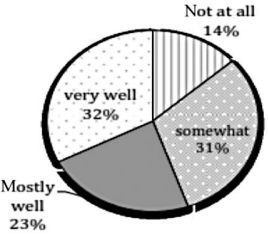

F

Group 2: Under 30 years with some college education

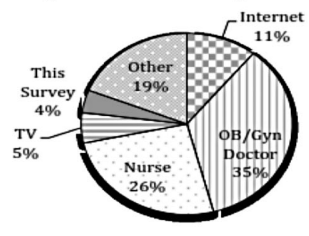

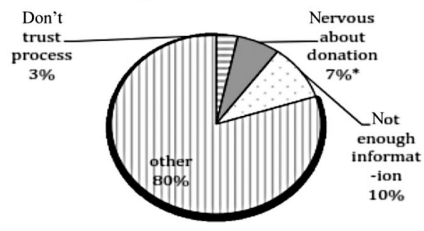

$* P=0.02$

Group 3: 30 years and over with up to high school education

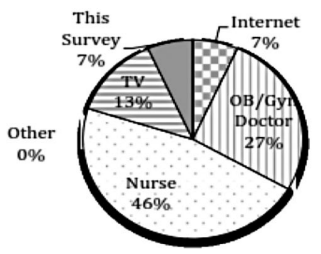

G

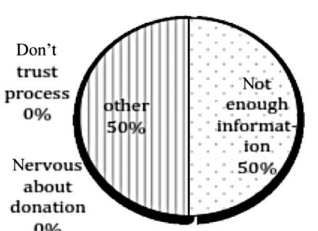

H

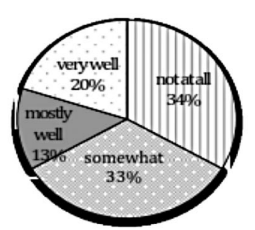

I

\section{Group 4: 30 years and over with some college education}

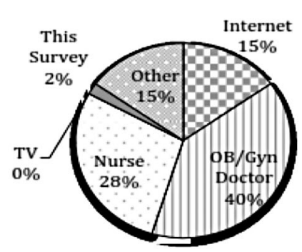

J

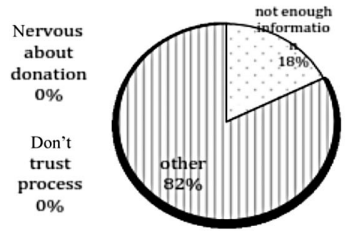

K

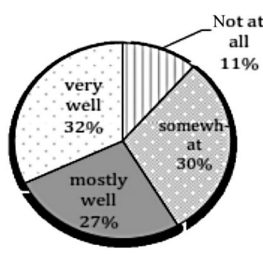

L

FIGURE 1 Potential UCB donors were divided into four groups based on age and education. Group 1: age less than 30 years with up to high school education. Group 2: age less than 30 years with some college education. Group 3: age older than 30 years with up to high school education. Group 4: age older than 30 years with some college education. Percentage of responses to questions regarding UCB donation are depicted in each group. The questions are indicated above pie charts in each column

Respondents with higher education beyond high school were more aware of the concept of UCB collection compared with their less educated counterparts, where 7-16\% (Groups 1 and 3) indicated that the current survey was their first introduction to this topic. In contrast, only $2-4 \%$ in Groups 2 and 4 indicated the same. However, despite this, there was no significant difference between the groups in how well they felt they understood the purpose of UCB donation. Respondents in Group 1 were significantly more likely to refuse to donate due to nervousness compared with other groups. This group was also less likely to be asked to donate UCB though they were the largest group in this survey. Due to the need to maintain anonymity on this study, participant's medical records were not examined. We were therefore unable to identify to what extent medical factors affected donation eligibility in any group.
Previous studies that aimed to assess women's knowledge and perceptions of UCB donation have described similar constraints to donation. Grossman et al. conducted a telephone survey of African American women in St. Louis area in 2005. They found that increasing awareness of UCB donation and education regarding the significance and process of donation improved the donation rates. ${ }^{10}$ In another survey of pregnant women in Halifax in 2003, Fernandez et al. found that most women wanted information on UCB collection from a healthcare professional or prenatal class and thought that physicians were best suited to discuss the process with their patients. Seventy percent of the respondents in this group reported poor or very poor knowledge about UCB banking. ${ }^{11} \mathrm{~A}$ similar survey of pregnant women in Australia in 2014 found that most were now aware of UCB banking, but knowledge levels varied. Women were less knowledgeable if they had a lower 
education level, were from rural areas, or from non-English speaking backgrounds. After the administration of relevant information, the proportion of women who reported they would consider donating UCB more than doubled. ${ }^{11}$ Similarly, a study in Rome in 2012 found a high level of awareness but low level of knowledge regarding UCB donation. Similar to our observation, this study also reported that only a minority of women would store UCB for private use. ${ }^{12}$ A study of non-Hispanic blacks and Hispanics in Illinois in 2010 found that most women from these ethnicities were unaware of UCB donation or its purpose. Further, there was confusion regarding public versus private banking, the actual collection procedure, and perceived harm to themselves or their babies. The length of the consent form was also identified as a burden on expectant mothers. ${ }^{13}$ Our survey, conducted in 2015 in a metropolitan setting, continues to reflect many of the obstacles identified over the years internationally. However, our finding that the percentage of women who donated UCB was similar across age and education demographics suggests that this gap is narrowing potentially due to efforts of the medical community in disseminating information.

UCB collection and storage data from SLCBB underscores the low number of units collected and processed from minority donors. Because only a small proportion of the collected units meet the criteria for banking due to increasing demand for products with higher cell counts, there is an even greater need to collect more units to meet these criteria especially in minorities where UCB cell counts are naturally lower. ${ }^{14,15}$ An additional factor worth considering is the increasing rate of DCC. Practices vary, as there are currently no standard recommendations regarding the exact duration of DCC or the appropriate gestational age for application of this maneuver. While DCC is not a contraindication to collection, UCB units collected following DCC can have lower volumes and cell counts and thus may affect cell dose requirements for banking. ${ }^{16}$

In summary, UCB banking and cell processing methods continue to evolve. As the need for UCB banking continues to grow, newer technology may help increase the availability of UCB units for transplant. Cord expansion techniques have had early success with hematopoietic stem and progenitor cell expansion ex vivo followed by successful use in transplantation. When mature, these methods may allow for smaller UCB unit retention, thus minimizing wastage for cell dose reasons, as they can support hematopoietic recovery. ${ }^{17-19}$ This survey identified barriers to UCB donation even among more educated women such as a lack of adequate information despite the proliferation of information technology and media sophistication. These barriers have continued to persist over time despite the recognition of a need to expand banking efforts. Allocating resources to support the presence of dedicated staff such as nurse aids or medical technicians during prenatal visits to discuss and encourage donation and complete the formalities of the consent process could increase efficiency at relatively low cost and effort. The discussion will need to emphasize the advantages associated with public banking of UCB products with no disadvantage to the donor or baby. Similarly, collaborating with providers to simplify the process of consent, collection, documentation, and transportation and making it uniform across regions can be beneficial. Efforts on the ground by invested parties to simplify and streamline the various aspects of UCB collection and reach minority communi- ties in parallel can further support the goal of cryopreserving and providing UCB products for transplant in larger numbers across multiple ethnicities.

\section{ACKNOWLEDGMENTS}

We are grateful to the providers and peripartum women who participated in this survey at each hospital.

\section{CONFLICT OF INTEREST}

The authors declare that there is no conflict of interest.

\section{REFERENCES}

1. Domen J, Gandy K, Dalal J. Emerging uses for pediatric hematopoietic stem cells. Pediatr Res. 2012;71:411-417.

2. Pasquini MC, Zhu X. Current uses and outcomes of hematopoietic stem cell transplantation: CIBMTR Summary Slides. 2015. Available at: https://www.cibmtr.org

3. King A, Kamani N, Bunin N, et al. Successful matched sibling donor marrow transplantation following reduced intensity conditioning in children with hemoglobinopathies. Am J Hematol. 2015;90:1093-1098.

4. Gragert L, Eapen M, Williams E, et al. HLA match likelihoods for hematopoietic stem-cell grafts in the U.S. registry. $N$ Engl J Med. 2014;371:339-348.

5. Hwang W, Samuel M, Tan D, Koh L, Lim W, Linn Y. A meta-analysis of unrelated donor umbilical cord blood transplantation versus unrelated donor bone marrow transplantation in adult and pediatric patients. Biol Blood Marrow Transplant. 2007;13:444-453.

6. Be The Match. https://bethematchorg/support-the-cause/donate-co rd-blood/cord-blood-is-changing-lives/federal-cord-blood-legislation/. 2015.

7. Rocha V, Labopin M, Sanz G, et al. Transplants of umbilical-cord blood or bone marrow from unrelated donors in adults with acute leukemia. N Engl J Med. 2004;351:2276-2285.

8. Gutman JA, Ross K, Smith C, Myint H, Lee CK, Salit R, Milano F, Delaney C, Gao D, Pollyea DA. Chronic graft versus host disease burden and late transplant complications are lower following adult double cord blood versus matched unrelated donor peripheral blood transplantation. Bone Marrow Transplant. 2016;51:1588-1593.

9. Marinho D, Neto J, Bonfim C, Funke V, Ribeiro L. Unrelated hematopoietic stem cell transplantation in the pediatric population: single institution experience. Rev Bras Hematol Hemoter. 2015;37:236-241.

10. Grossman B, Watkins A, Fleming F, Debaun M. Barriers and motivators to blood and cord blood donations in young African-American women. Am J Hematol. 2005;78:198-202.

11. Fernandez C, Gordon K, Van den Hof M, Taweel S, Baylis F. Knowledge and attitudes of pregnant women with regard to collection, testing and banking of cord blood stem cells. CMAJ. 2003;168:695-698.

12. Screnci M, Murgi E, Pirrè G, et al. Donating umbilical cord blood to a public bank or storing it in a private bank: knowledge and preference of blood donors and of pregnant women. Blood Transfus. 2012;10:331337.

13. Rucinski D, Jones R, Reyes B, Tidwell L, Phillips R, Delves D. Exploring opinions and beliefs about cord blood donation among Hispanic and non-Hispanic black women. Transfusion. 2010;50:1057-1063.

14. Wofford J, Kemp J, Regan D, Creer M. Ethnically mismatched cord blood transplants in African Americans: the Saint Louis Cord Blood Bank experience. Cytotherapy. 2007;9:660-666. 
15. Page K, Mendizabal A, Betz-Stablein B, et al. Optimizing donor selection for public cord blood banking: influence of maternal, infant and collection characteristics on cord blood unit quality. Transfusion. 2014;54:340-352

16. Allan D, Scrivens N, Lawless T, et al. Delayed clamping of the umbilical cord after delivery and implications for public cord blood banking. Transfusion. 2016;56:662-665.

17. de Lima M, McNiece I, Robinson S, et al. Cord-blood engraftment with ex vivo mesenchymal-cell coculture. N Engl J Med. 2012;367:23052315.

18. Delaney C, Heimfeld S, Brashem-Stein C, Voorhies H, Manger R, Bernstein I. Notch-mediated expansion of human cord blood progenitor cells capable of rapid myeloid reconstitution. Nat Med. 2010;16:232236.
19. Horwitz M, Chao N, Rizzieri D, et al. Umbilical cord blood expansion with nicotinamide provides long-term multilineage engraftment. J Clin Invest. 2014;124:3121-3128.

How to cite this article: Bhandari R, Lindley A, Bhatla D, Babic A, Mueckl K, Rao R, Brooks P, Geile V, Gross G, AlHosni M, and Shenoy S. Awareness of cord blood collection and the impact on banking. Pediatr Blood Cancer. 2017;64:e26412. doi:10.1002/pbc.26412. 